\title{
A microcomputer-based laboratory for psychopathology research in rural settings
}

\author{
WILL SPAULDING, DAVID S. HARGROVE, W. J. CRINEAN, and THOMAS MARTIN \\ University of Nebraska, Lincoln, Nebraska 68588
}

\begin{abstract}
An Apple-based computer system for research use in rural mental health settings is described. Hardware and software modifications are detailed. Techniques to aid in the acceptance of psychopathology research programs in these rural settings are discussed.
\end{abstract}

The past 10 years have seen some significant advances in the experimental psychopathology of severe chronic disorders. Laboratory on-line computer systems have played a central role in these advances for several reasons. One is a proliferation of complex experimental paradigms. Computers can be programmed to efficiently control and administer a huge diversity of psychological experiments. For example, among measures of current interest are reaction time (under complex, varying stimulus conditions), continuous vigilance tasks, backward-masking thresholds, visual size estimation, perceptual performance under ipsimodal and crossmodal distraction, eye tracking, visual pattern recall and recognition, conceptual sorting tasks, and psychophysiological evoked response measures. Many of these are impossible without on-line computer control of some sort. A single computer with a few relatively inexpensive peripheral devices is usually cheaper and more flexible than the many specialized instruments required for a laboratory to conduct such a diversity of experiments.

There is a crucial need for this wide range of experimental paradigms. Disorders such as "schizophrenia" are now considered by most to be heterogeneous amalgams of many more specific psychological abnormalities. Researchers seldom assume anymore that there is a single measurement or psychological construct that holds the "key" to schizophrenia. The current focus is instead on relationships between various psychological abnormalities (detected in the laboratory) and important clinical factors. The latter tend to vary considerably within diagnostic groups. Clinical variables of interest may include behavioral symptomatology, drug responsiveness, success of psychotherapy, social adjustment, and hospital recidivism, among others.

With so many potential relationships to explore, and with simple categorizations like schizophrenia of such limited value, modern research strategy requires efficient collection and management of vast amounts of data-in

The project described herein was supported in part by the College of Arts and Sciences, University of Nebraska-Lincoln, by the UN-L Research Council, and by NIH Biomedical Research Support Grant RR-07055. both laboratory and clinical settings. As a result, on-line computers have become practically indispensible.

Very recently, a new factor has begun to influence the directions taken by psychopathology research. Rural mental health has been declared by the National Institute of Mental Health (NIMH) to be an area of high funding priority for clinical training and research. From the experimental psychopathologist's point of view, this is a highly appropriate policy, since so little is known about rural mental health. Almost the entire knowledge base of experimental psychopathology is built on studies of urban, usually institutionalized, populations. To our knowledge, only one study has been reported that examined the psychology of abnormal behavior in a rural setting (Weinstein, Eck, \& Lyerly, 1969). Others have been limited to epidemiological data (Dohrenwend \& Dohrenwend, 1969; Husaini \& Neff, 1979; Mazer, 1976; Schwab, Warheit, \& Holzer, 1972).

Although cross-cultural data would suggest that major psychiatric disorders occur with roughly equal frequency across sociocultural settings, little more than that is known. Is pathological behavior expressed similarly in rural and urban settings? Is the response of the patients' social support system comparable? More data are urgently needed on the nature of rural psychopathology, for use by the inevitable influx of clinicians into rural settings. In addition, urban-rural contrasts may address some important theoretical issues.

For example, evidence is accumulating that clinical behaviors (the "symptoms": hallucinations, delusions, etc.) do not directly reflect etiological processes. Symptoms do not predict clinical outcome as well as measures of intellectual functioning or socialdevelopmental level do. It is often theorized that relatively subtle psychological deficits (e.g., inattention or distractibility) compromise social functioning but do not directly cause symptoms. Many symptoms may therefore reflect social consequences of psychological impairment. Among other possible functions, those symptoms would serve to maintain a "crazy patient" social role, enabling the patient to achieve a modicum of social stability and maintain access to mental health services. Research could explore social vs. psychological determinants of symptoms by contrasting individuals who 
have similar psychological deficits but who live in different social settings. The rural-urban dimension provides an ideal social setting contrast for that type of study. With this and other issues to explore, rural settings represent attractive possibilities to academic researchers in experimental psychopathology.

The strategies and tactics that have evolved in our research group are the product of simultaneous consideration of theoretical psychopathology and the realities of rural mental health. The point of view of a clinical psychologist working in a rural setting includes practical considerations that must be respected by academic experimental psychopathologists. Therefore, it is important to include in this description of our research methodology a discussion of the rapprochement of university laboratory and rural clinic.

From the clinician's point of view, the NIMH priority on the mental health of rural and isolated people is because of the unique problems that affect the mental and emotional functioning of these people and impede mental health service delivery. Persons and families living in rural areas are vulnerable to mental disorder for a number of reasons. The geographical distance to necessary resources for physical, educational, and cultural well-being is usually great, frequently requiring considerable time or difficulty in coping with natural barriers. Second, rural communities have experienced a slow deterioration because of the outward migration of young persons. This results in the depletion of human and economic resources. Frequently, the brighter young persons leave the rural area for opportunities in urban communities. The rural community, as a result, loses the most important role models and human resources necessary for the development of strong communities.

Problems that affect the delivery of mental health and other human services in rural areas include the geographical distances for which agencies are responsible, lower tax bases for the support of mental health and human service programs, multiple units of government with which to negotiate for public funds, less appeal for professional mental health manpower resulting in recruitment and retention difficulties, and increased costs of manpower and service delivery.

These factors create an environment that can be either discouraging to research or encouraging, depending on the strategy of the researchers. On one hand, clinic administrators cannot afford to allocate money or manpower to research. On the other hand, if research leads to data that can increase the efficiency or effectiveness of an agency, collaboration with researchers can be very attractive. Similarly, geographical isolation can be seen as a barrier to data collection or as a natural subject-grouping factor.

Rural clinicians generally are aware of the problems associated with the inadequate knowledge base in rural psychopathology. Also, they are sensitive to the problems of using existing diagnostic criteria to identify and understand abnormal behavior. Those problems are, in fact, compounded in rural settings. Diagnostic criteria, whatever their shortcomings, are developed in urban populations. There is no reason to assume that such criteria would be more useful or less misleading in rural populations. The more specific social and behavioral variables often used by psychopathologists offer more to rural clinicians than diagnostic categories do. A researcher who made these measurements available to clinical collaborators would be providing a valuable service.

There is a further advantage in the use of highly specific clinical variables instead of diagnosis. The concept of "rural" is heterogeneous, and tolerance for deviancy seems to vary among rural areas of the country. It follows that the best investigation of rural psychopathology would be confined to restricted, homogeneous areas. The prevalence, intensity, etiology, and behavioral expression of a given psychopathological disorder in rural Mississippi likely will differ from disturbance in rural California or rural New England. While this assertion cannot be validated empirically, it seems to be a sound assumption on which to base considerations of research on rural psychopathology.

Because of these considerations, rural psychopathological research is best conducted in the various rural locales in collaboration with their service delivery systems. Unfortunately, most rural service delivery systems are not committed to psychopathological research because of the lack of funds, resources, and time. Universities frequently are unable to engage in rural psychopathological research because they are located in predominantly urban areas and do not have sufficient relationships to the rural service providers. When the relationship between the rural service provider and the university is sufficient, the resources of the two institutions can be combined to provide a fertile field for significant research.

The research teams of the rural mental health specialty of the clinical psychology training program at the University of Nebraska-Lincoln are attempting to solidify relationships to enable significant psychopathological research to be carried out. There are two components of this effort. The first is the relationship to the psychopathology research program with the clinical program, particularly with regard to the use of small computer systems. The second is in the utilization of practicum training sites for the rural specialty as settings in which psychopathological research may be conducted. Since most small rural mental health service delivery programs do not have computer accessibility or research-oriented personnel, the clinical psychology training program is able to work through the practicum placement system to provide the needed computer capability and manpower.

The effort of these research teams reaches beyond the practicum experience of the student-clinicians to a 
collaborative model of research that is emphasized by the rural specialty. The collaborative model attempts to utilize a number of persons and facilities to carry out research that may be generated by the university or a specific service delivery agency. Usually, by virtue of location and common experience, the university can provide the coordination of the research efforts, enabling many agencies, students, and professionals to collaborate for meaningful research.

Such collaborative research enables investigators to address both homogeneous and heterogeneous characteristics to determine the uniqueness of psychopathology to specific areas. The ability to systematically collect data from various rural areas, heretofore too expensive for a single researcher, is enhanced by the collaborative model.

Our experimental psychopathology laboratory evolved to meet the demands of the collaborative model. Many of the laboratory's design prerequisites follow directly from the needs of a stationary urban laboratory, and others are related to the implications of rural research. The prerequisites can be summarized as: (1) ability to control experiments in a wide range of laboratory paradigms, (2) ability to manage a large data base, including measures of community social adjustment and clinical symptomatology, as well as laboratory variables, (3) mobility to travel from the home laboratory to distant clinical settings, (4) software sophisticated enough to allow self-documenting structured programming and to be used by generations of transient graduate students, (5) affordability, and (6) ability to provide useful, relatively immediate service to clinical agencies and personnel.

\section{HARDWARE AND LOW-LEVEL SOFTWARE}

We have built our laboratory around the Apple II "Plus" system because it meets all of the previously discussed prerequisites. The system consists of: 48K bytes of RAM, an Apple serial interface card, an Apple language card, an Apple clock (Mountain Hardware), an IP125 dot matrix printer (Integral Data Systems), two Apple disk drives and interface card, a Micromodem (D.C. Hays), a 12-in. black-and-white monitor (Leedex, Inc.), a 19-in. color TV (Sony, Inc.), and a custom-built interface. The total cost of the system was less than $\$ 6,000$.

We have made two very simple modifications in the computer itself. The first allows the computer to blank or unblank video displays under program control. The second modification allows a program to monitor the video synchronization pulse. This allows more precise timing of video display presentations. Together, the two modifications permit the computer to function as a tachistoscope. The hardware modifications are described in detail by Reed (1979). (For further details on potential problems with computer-CRT tachistoscope displays, see DiLollo, 1979; Lincoln \& Lane, 1980; Sidowski, 1978, pp. 754-795).
We have also designed a special interface box that is connected to the internal Apple II game connector. This interface facilitates access to the internal game connector without requiring one to open the computer case each time he wants to use the connector. Also, it expands the computer's interactive capabilities to provide a multifunction subject response console for our experiments.

The game connector consists of four TTL-level outputs called annunciators, four analog-to-digital (A/D) inputs for paddle or joystick controls, and three TTL-level inputs for bipolar switches such as pushbuttons. The connector also provides lines for power (ground, $+5 \mathrm{~V}$ ).

The main component of the interface is a multiplexing circuit (see Figure 1) that allows the computer to read a maximum of seven pushbuttons or TTL inputs, rather than just the three provided for. This is done with external logic that converts each buttonpress into a 3-bit binary number, which the computer then decodes.

Our interface has two additional functions that are related to video blanking and the monitoring of the vertical synchronization pulse. The interface is designed so that the user can switch select the video blanking function. There is a simple toggle switch that either completely disables the video blanking or allows the computer to control the video blanking, using one of the annunciator outputs. A red light-emitting diode (LED), when illuminated, indicates that the video blanking is disabled and not under computer control. If the switch is off and if the video blanking output is connected to an annunciator output, every time this output goes to logic "l" (approximately $5 \mathrm{~V}$ ), the video signal will be displayed; otherwise, it is stopped. A green LED lights when the computer has turned the video blanking off.

The monitoring of the vertical synchronization pulse has caused us certain problems. The only way to monitor it is by using one of the three conventional pushbutton inputs. This, of course, prevents the input's being used to detect other events. We have dealt with this problem by building a second logic system in the interface that allows the computer to read either the normal buttons and/or expanded inputs or the vertical synchronization pulse. This is controlled by one of the annunciator outputs. When the vertical synchronization system has been enable by the computer, a green LED lights. The logic for this system is diagrammed in Figure 1.

The construction of the interface required about $6-8 h$. It cost about $\$ 75$. Either TTL logic or CMOS logic is suitable for this circuit because power consumption and speed are not critical. The schematic diagram (Figure 1) provides all pin outs and component values. Wire wrapping is the easiest and most convenient form of construction, as it requires the least amount of specialized equipment.

We have had to write a number of specialized 


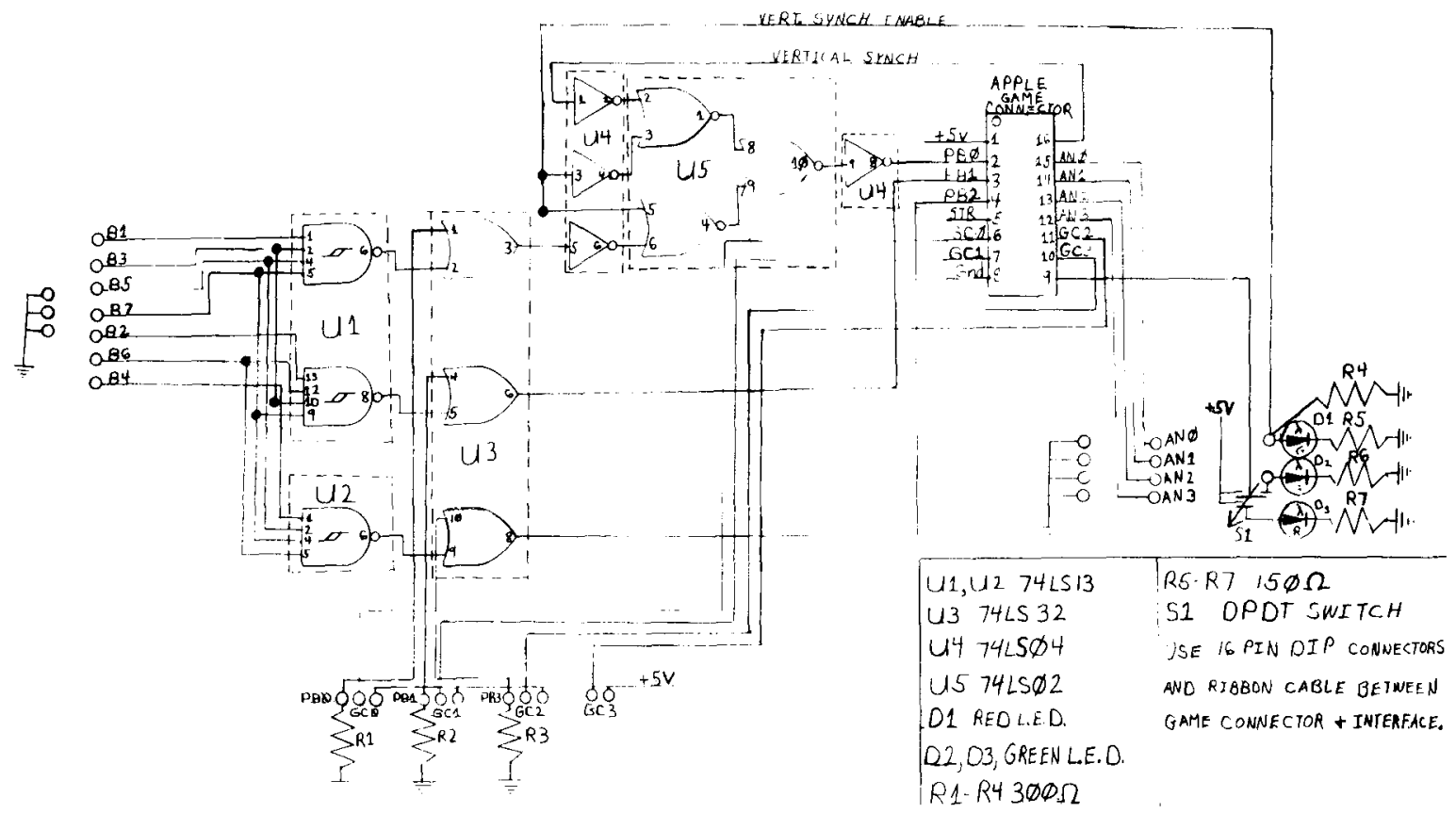

Figure 1. Schematic diagram of the subject response console in terface.

assembly-level programs to support the hardware modifications and otherwise implement the system. One of these programs is used to set and reset the game connector annunciator outputs. The PASCAL system provided by Apple has a bug that prevents correct operation of these outputs. The correct program is listed in the Apple PASCAL reference manual. The software for reading input from the game connector/ console interface is listed in the appendix.

We also had difficulty interfacing our real-time clock with the rest of the system because Apple PASCAL has no allowance for a real-time clock. This problem was compounded because the software provided by Mountain Hardware was all written in BASIC. Since our own assembly software was written, Mountain Hardware has rectified this problem, and they now provide PASCAL-based software for their clock. The Mountain Hardware software has several features that our software (see appendix for listings) does not. However, their software takes several milliseconds to read the clock, whereas ours can read the clock in about $.5 \mathrm{msec}$. This makes our software more suitable for applications in which millisecond-level timing is critical (e.g., backward masking). The software we have developed for timing and presenting tachistoscopic displays is listed in the appendix.

A great advantage of the Apple PASCAL system is that specialized low-level programs such as these can be stored in a library file on disk. They can be structured so that they are automatically linked into high-level programs with single-word commands. Once filed, they can be accessed by our relatively unsophisticated student programmers who use them in higher level programming.
One final advantage of our Apple system is its ability to incorporate psychophysiological instrumentation. There are two alternatives that we are currently considering. The first is to purchase individual transducers and preamplifiers and route them to the computer through the Apple A/D board. This would cost about $\$ 1,000$ for power supply and interfacing plus about $\$ 500$ per channel. The programming required would be substantial.

The second alternative is a more fully developed system by Toomin Instrument Company. It has four channels, each of which can be switched by computer to different physiological modalities (EEG, GSR, heart rate, etc.). The system uses an infrared link between preamps and the computer. This eliminates noise due to long wire leads and permits greater subject mobility. With software, the system would cost about $\$ 7,000$. It would require little software modification because it is designed for use with an Apple computer.

\section{THE CLINICAL/DEMOGRAPHIC DATA BASE}

In traditional psychopathology research, nonexperimental data (e.g., diagnosis, medication, history, etc.) are typically collected from clinical records by a member of the research staff. That is an expensive timeconsuming process, and the information in psychiatric records is often too vague and unstructured to be useful in research. The problem is compounded by the fact that the most important independent variables of current interest are not customarily included in records. For example, subjective estimates of a patient's premorbid adjustment level or current social adjustment 
level are seldom seen in psychiatric records, much less objective measurements of those factors. In many cases, research requires immediate behavioral data: for example, checklist-type data on performance in a clinical interview. This is, of course, impossible to derive from clinical records.

The need for such comprehensive and updated data puts researchers in a difficult position. Either members of the research staff must be trained to do the necessary clinical interviews or clinical staff must be retrained to conduct their activities in conformity with data gathering needs. The former may be impossible due to the expense of training clinically inexperienced individuals or to professional/confidentiality constraints. The latter is a particularly dismal alternative in rural settings, in which clincial staff may be overworked and uninvested or inexperienced in research.

We have found that clinical staff are more willing to cooperate in data collection when two conditions are fulfilled: (1) The collection activities conform closely to their accustomed clinical procedures, and (2) there is a clear and relatively immediate benefit in terms of feedback of useful information or (even better) time savings. We have designed our data collection system to address those conditions. As a result, we have been reasonably successful in securing cooperation from clinical staff.

The central feature of the clinical data system is a semistructured intake/reassessment interview. The interview was developed in cooperation with several clinicians at a local community mental health center. The clinicians provided feedback about the interview's conformation to their customary interviewing styles and the required information content. The interview is composed of three sections. Section 1 includes identification, psychiatric status, case history, and family history. Section 2 is a modification of the Social Adjustment Scale (Schooler, Hogarty, \& Weismann, 1977), a comprehensive objective evaluation of current social adjustment. Section 3 is a modification of the Inpatient Multidimensional Psychiatric Scale (Lorr \& Klett, 1966), a factoranalyzed behavior checklist focusing on severely disturbed behavior. Sections 1 and 2 are completed in checklist fashion during the interview. Section 3 is completed immediately afterward.

Since the interview is predominantly a checklist, it could easily be reformatted for automatic light-sensor reading. Due to the availability of inexpensive clerical assistance, we input the data with an interactive program over the computer's keyboard. The data are stored in a file of about 220 integer and Boolean values and several character strings. The latter are for idiographic data, such as names and direct quotes.

A second important feature of the system is a program that writes a narrative clinical report based on the data from the interview. The report includes several sections most typical of intake reports: identifying data, presenting problem, personal and family history, mental status examination, diagnosis, and disposition.
The diagnosis is rendered by a subprogram that reaches a diagnosis based on historical and symptomalogical data; the intake interviewer is thus relieved of diagnostic work. The report would ordinarily be dictated by the interviewer; thus, in addition to time saved on diagnosis, clinical staff save $1-2 \mathrm{~h}$ of dictation and clerical time in return for gathering our data.

The advantages of the PASCAL language system are particularly relevant to our system's ability to provide clinically useful feedback. Individual agencies have quite different formats for intake reports, so it is important for the program to be easily modifiable. Similarly, different agencies may require different elements from our data base. For example, our pilot agency uses a local modification of the Brief Psychiatric Rating Scale (BPRS) as an in-house outcome assessment instrument. It is a relatively simple programming task to convert the interview data into BPRS scores. In doing so, we were thus able to offer the agency an additional service and assist their program evaluation activities.

Presently, there are numerous software packages available that perform various psychological services, ranging from interactive clinical interviews to test scoring and interpretation. Many of these are programmed in BASIC, which is in the Apple II "Plus" language repertoire. We therefore have the potential capability of responding to a wide range of agency needs, should such services be necessary in the future to establish cooperation in clinical settings.

\section{REFERENCES}

Apple Computen, Inc. Apple PASCAL operating system reference manual. Cupertina, Calif: Author, 1980.

DiLouro, V. Luminous calibration of oscilloscopic displays. Behavior Research Methods \& Instrumentation, 1979, 11, 419-421.

Dohrewend, B. P., \& Dohrenwend, B. S. Social status and psychological disorder. New York: Wiley Interscience, 1969.

Husaini, B. A., \& NEFF, J. A. The mental health needs of a rural Tennessee community: A preliminary report. In G. Landsberg, W. D. Neigher, R. J. Hammer, C. Windle, \& J. R. Woy (Eds.), Evaluation in practice: $A$ sourcebook of program evaluation studies from mental health care systems in the United States [National Institute of Mental Health, DHEW Publication No. (ADM) 78-763]. Washington, D.C: U.S. Government Printing Office, 1979.

Lincoln, C., \& LANE, D. Reaction time measure errors resulting from the use of CRT displays. Behavior Research Methods \& Instrumentation, 1980, 12, 55-57.

LORR, M., \& KLETT, C. Inpatient multidimensional psychiatric scale: Manual. Palo Alto, Calif: Consulting Psychologists Press, 1966.

Mazer, M. People and predicaments. Cambridge: Harvard University Press, 1976.

Mountain Hardware, Inc. Apple clock operating manual (Revision 2). Santa Cruz, Calif: Author, 1979.

REev, A. V. Microcomputer display timing: Problems and solutions. Behavior Research Methods \& Instrumentation, 1979, $11,572-576$.

Schooler, N., Hogarty, G., \& Weismann, M. Social adjustment Scale II. In W. Hargreaves, C. Atkisson, \& I. Sorenson (Eds.) Resource materials for community mental health program evaluation. Rockville, Md: National Institute of Mental Health, 1977.

Schwab, J., Warheit, G., \& Holzer, C. Mental health: Rural- 
urban comparisons. 4th International Congress of Social Psychiatry, 1972, p. 237. (Abstract)

Sidowski, J. B. (Ed.), Behavior Research Methods \& Instrumentation (Vol. 10). Austin, Tex: Psychonomic Society, 1978.

Weinstein, E., Eck, R., \& Lyerly, O. Conversion hysteria in Appalachia. Psychiatry, 1969, 32, 334-341.

\section{APPENDIX}

This appendix provides complete listings of the machine-level programs needed to run our system. The programs are written in 6502 assembly language. For additional information, please see the Apple PASCAL reference manual (pp. 94-124) and 6502 assembly language programming by Lance A. Leventhal. All of the programs listed here can be placed in the PASCAL library and called like any other PASCAL intrinsic.

The first three short programs are MACRO commands that are used by the other programs for housekeeping functions.

$\begin{array}{ll}\text { MACRO } & \text { POP } \\ \text { PLA } & \\ \text { STA } & \% 1 \\ \text { PLA } & \\ \text { STA } & \% 1+1 \\ \text {.ENDM } & \\ \text {.MACRO } & \text { PUSH } \\ \text { LDA } & \% 1+1 \\ \text { PHA } & \\ \text { LDA } & \% 1 \\ \text { PHA } & \\ \text {.ENDM } & \\ \text { MACRO } & \text { POPBIAS } \\ \text { PLA } & \\ \text { PLA } & \\ \text { PLA } & \\ \text { PLA } & \\ \text {.ENDM } & \end{array}$

The next four programs are used to start clock, stop clock, zero clock, and read clock (the real-time clock). All addresses for the clock are in hexidecimal and are set for the clock's being set in Slot 4 in the Apple. If this is changed, all addresses must be altered accordingly. For additional information, see the Mountain Hardware Apple clock reference manual.

$\begin{array}{lll} & \text {.PROC } & \text { STOPCLOCK } \\ \text { RETURN } & \text {.EQU } & 0 \\ & \text { POP } & \text { RETURN } \\ & \text { LDA } & \text { OCOC6 } \\ & \text { PUSH } & \text { RETURN } \\ & \text { RTS } & \\ \text { RETURN1 } & \text {.PROC } & \text { STARTCLOCK } \\ & \text {.EQU } & 2 \\ & \text { POP } & \text { RETURN1 } \\ & \text { LDA } & \text { OCOC5 } \\ & \text { PUSH } & \text { RETURN1 } \\ & \text { RTS } & \\ & \text {.PROC } & \text { ZEROCLOCK } \\ \text { RETURN2 } & \text {.EQU } & 4 \\ & \text { POP } & \text { RETURN2 } \\ & \text { CLC } & \\ & \text { LDA } & \text { OCOC6 } \\ \text { LOOP } & \text { LDA } & \text { OCOC3 } \\ & \text { ORA } & \text { OC0C2 } \\ & \text { BEQ } & \text { DONE } \\ & \text { LDA } & \text { OCOC7 } \\ & \text { JMP } & \text { LOOP }\end{array}$

$\begin{array}{lll}\text { DONE } & \text { PUSH } & \text { RETURN2 } \\ & \text { RTS }\end{array}$

This procedure uses one parameter to select between milliseconds and seconds ( 0 selects milliseconds and 1 selects seconds).

\begin{tabular}{|c|c|c|}
\hline &.$F U N C$ & READCLOCK,1 \\
\hline RETURN3 & EQU & 6 \\
\hline TEMP1 &. $\mathrm{EQU}$ & 8 \\
\hline TEMP2 &. $\mathrm{EQU}$ & 9 \\
\hline LOBYTE &. $\mathrm{EQU}$ & 10. \\
\hline HIB YTE &. $\mathrm{EQU}$ & 11. \\
\hline TEMP3 & EQU & 12. \\
\hline \multirow[t]{16}{*}{ TEMP4 } &. $\mathrm{EQU}$ & 13. \\
\hline & $\begin{array}{l}\text { POP } \\
\text { POPBIAS } \\
\text { PLA }\end{array}$ & RETURN3 \\
\hline & BNE & SECONDS \\
\hline & LDA & $0 \mathrm{COC} 3$ \\
\hline & STA & TEMP3 \\
\hline & LDA & $0 \mathrm{COC} 4$ \\
\hline & STA & TEMP4 \\
\hline & PLA & \\
\hline & LDA & \#100. \\
\hline & STA & TEMP2 \\
\hline & LDA & TEMP 3 \\
\hline & AND & \#OF \\
\hline & STA & TEMP1 \\
\hline & LDA & $\# 0$ \\
\hline & STA & HIBYTE \\
\hline & LDX & $\# 8$ \\
\hline \multirow[t]{8}{*}{ SHIFT } & ASL & A \\
\hline & ROL & HIBYTE \\
\hline & ASL & TEMP2 \\
\hline & $\mathrm{BCC}$ & CHCNT \\
\hline & CLC & \\
\hline & $\mathrm{ADC}$ & TEMP1 \\
\hline & $\mathrm{BCC}$ & CHCNT \\
\hline & INC & HIBYTE \\
\hline \multirow[t]{21}{*}{ CHCNT } & DEX & \\
\hline & BNE & SHIFT \\
\hline & STA & LOBYTE \\
\hline & LDA & TEMP4 \\
\hline & AND & $\# 15$. \\
\hline & STA & TEMP1 \\
\hline & LDA & TEMP4 \\
\hline & AND & $\# 240$ \\
\hline & CLC & \\
\hline & ROR & A \\
\hline & ROR & $\mathbf{A}$ \\
\hline & ROR & $\mathbf{A}$ \\
\hline & STA & TEMP2 \\
\hline & ASL & A \\
\hline & ASL & $\mathbf{A}$ \\
\hline & CLC & \\
\hline & $\mathrm{ADC}$ & TEMP1 \\
\hline & $\mathrm{ADC}$ & TEMP2 \\
\hline & $\mathrm{ADC}$ & LOBYTE \\
\hline & $\mathrm{BCC}$ & PUSHER \\
\hline & INC & HIBYTE \\
\hline \multirow[t]{7}{*}{ PUSHER } & STA & LOBYTE \\
\hline & LDA & HIBYTE \\
\hline & PHA & \\
\hline & LDA & LOBYTE \\
\hline & PHA & \\
\hline & PUSH & RETURN3 \\
\hline & RTS & \\
\hline SECONDS & PLA & \\
\hline
\end{tabular}




\begin{tabular}{|c|c|c|c|c|}
\hline $\begin{array}{l}\text { LDA } \\
\text { AND } \\
\text { CLC }\end{array}$ & $\begin{array}{l}0 \mathrm{COC} 3 \\
\# 240 .\end{array}$ & MIDBIT & $\begin{array}{l}\text { ADC } \\
\text { STA } \\
\text { CLC }\end{array}$ & $\begin{array}{l}\# 01 \\
\text { TEMP3 }\end{array}$ \\
\hline ROR & A & & ROL & $0 \mathrm{CO} 062$ \\
\hline ROR & A & & $\mathrm{BCC}$ & HIBIT \\
\hline ROR & $\mathbf{A}$ & & CLC & \\
\hline ROR & A & & LDA & TEMP3 \\
\hline STA & LOBYTE & & $\mathrm{ADC}$ & $\# 02$ \\
\hline LDA & $0 \mathrm{COC} 2$ & & STA & TEMP3 \\
\hline AND & \#15. & HIBIT & CLC & \\
\hline CLC & & & ROL & $0 \mathrm{CO63}$ \\
\hline ROL & A & & $\mathrm{BCC}$ & STOP \\
\hline ROL & A & & CLC & \\
\hline ROL & A & & LDA & TEMP3 \\
\hline ROL & A & & $\mathrm{ADC}$ & \#04 \\
\hline $\mathrm{ADC}$ & LOBYTE & & STA & TEMP3 \\
\hline STA & LOBYTE & STOP & LDA & $\# 0$ \\
\hline LDA & $0 \mathrm{COC} 2$ & & PHA & \\
\hline AND & $\# 240$. & & LDA & TEMP3 \\
\hline CLC & & & PHA & \\
\hline ROR & $\mathbf{A}$ & & PUSH & RETURN \\
\hline ROR & A & & RTS & \\
\hline
\end{tabular}

This subroutine uses vertical synch pulses to time the display. When it is doing so, SW1 is unavailable for reading other input.

\begin{tabular}{lll} 
VSYNC & LDA & 0C05F \\
& CLC & \\
& ROL & 0C061 \\
& BCC & VSYNC \\
HIGH & CLC & \\
& ROL & 0C061 \\
& BCS & HIGH \\
& DEX & \\
& BEQ & END \\
END & JMP & VSYNC \\
& LDA & OC05E \\
& RTS & \\
\hline
\end{tabular}

This program sets the annunciator outputs on the game connector. It is identical to the listing in the PASCAL manual for the Apple. Our version of the Apple PASCAL system has a bug in it that prevents your using the routines provided for this purpose by Apple. This bug is quite likely to be corrected on later updates of the system.

$\begin{array}{lll} & \text {.PROC } & \text { TTLI0,2 } \\ \text { RETURN6 } & \text {.EQU } & 21 . \\ & \text { POP } & \text { RETURN6 } \\ \text { PLA } & \\ \text { LSR } & \text { A } \\ \text { PLA } & \\ \text { PLA } & \\ \text { AND } & \# 03 \\ \text { ROL } & \text { A } \\ \text { TAY } & \\ \text { LDA } & 0 \text { CO58,Y } \\ \text { PLA } & \\ \text { PUSH } & \text { RETURN6 } \\ \text { RTS } & \\ & \text {.END } & \end{array}$

This routine is used to control the video system, so it can be used as a tachistoscopic display.

$0 \mathrm{C061}$

MIDBIT

$\begin{array}{ll}\text { BCC } & \text { MIDBIT } \\ \text { LLC } & \\ \text { LDA } & \text { TEMP3 }\end{array}$

.PROC DISPLAYCONTROL,1

.PUBLIC STIMTIME,DELAYTIME,MASKTIME

RETURN5 .EQU 18. 


$\begin{array}{lll}\text { TEMP5 } & \text {.EQU } & 20 . \\ & \text { POP } & \text { RETURN5 } \\ & \text { LDA } & \text { \#0A0 } \\ & \text { STA } & \text { 0400 } \\ & \text { LDX } & \text { STIMTIME } \\ & \text { LDA } & \text { 0C05D } \\ & \text { LDA } & \text { OC051 } \\ & \text { LDA } & \text { OC054 } \\ & \text { JSR } & \text { VSYNC } \\ & \text { PLA } & \\ & \text { STA } & \text { TEMP5 } \\ & \text { BEQ } & \text { BLANK } \\ & \text { LDA } & \text { OC050 } \\ & \text { LDA } & \text { OC057 } \\ & \text { LDA } & \text { OC053 } \\ & \text { LDA } & \text { OC054 } \\ & \text { JMP } & \text { TIME } \\ \text { BLANK } & \text { LDA } & \text { OC05C } \\ \text { TIME } & \text { LDX } & \text { DELAYTIME }\end{array}$

$\begin{array}{lll} & \text { BEQ } & \text { SKIP } \\ \text { SKIP } & \text { JSR } & \text { VSYNC } \\ & \text { LDX } & \text { MASKTIME } \\ & \text { BEQ } & \text { RESET } \\ & \text { LDA } & \text { 0C05D } \\ & \text { LDA } & \text { 0C051 } \\ & \text { LDA } & \text { 0C055 } \\ & \text { JSR } & \text { VSYNC } \\ \text { RESET } & \text { LDA } & \text { TEMP5 } \\ & \text { BEQ } & \text { GRAPH } \\ & \text { LDA } & \text { OC05C } \\ & \text { JMP } & \text { RESET2 } \\ \text { GRAPH } & \text { LDA } & \text { OC05D } \\ \text { RESET2 } & \text { LDA } & \text { OC050 } \\ & \text { LDA } & \text { OC054 } \\ & \text { LDA } & \text { OC057 } \\ & \text { LDA } & \text { OC053 } \\ \text { HALT } & \text { PLA } & \\ & \text { PUSH } & \text { RETURN5 }\end{array}$

